\title{
Linguagem e verdade em Walter Benjamin: pensando as tensões do nosso tempo
}

\author{
Martha D'Angelo ${ }^{1}$
}

\begin{abstract}
Resumo: $O$ artigo investiga a relação entre linguagem e verdade no pensamento de Walter Benjamin, destacando sua compreensão da natureza do saber filosófico, a crítica às teorias epistemológicas da filosofia institucional e a função da faculdade mimética na gênese da linguagem. $\mathrm{O}$ texto analisa as afinidades da filosofia da linguagem de Benjamin com as colagens/montagens dadaístas e surrealistas, observando as particularidades e a originalidade da metodologia utilizada no trabalho das Passagens. Conclui refletindo sobre o caráter dialético da cultura, o compromisso da educação com a verdade e a prioridade no combate à barbárie.
\end{abstract}

Palavras-chave: Walter Benjamin. Crítica da cultura. Linguagem. Surrealismo.

\section{Language and truth in Walter Benjamin: thinking on the tensions of our time}

\begin{abstract}
The article examines the relationship between language and truth in Walter Benjamin's thinking, pointing out his understanding of the nature of philosophical knowledge, the critique of the epistemological theories of institutional philosophy and the function of the mimetic faculty in the origins of language. The text discusses the affinities of Benjamin's philosophy of language with dadaist and surrealist collages/assemblages, noting the particularities and originality of the methodology employed in the Arcades Project. The article concludes with a reflection on the dialectical nature of culture, the commitment of education with truth and the priority of the fight against barbarism.
\end{abstract}

Palavras-chave: Walter Benjamin. Critique of culture. Language. Surrealism.

${ }^{1}$ Martha D’Angelo é doutora em Filosofia pela UFRJ (2000), professora da Faculdade de Educação e do Programa de Pós-graduação em Educação da UFF. Publicou Arte política e educação em Walter Benjamin (Loyola, 2006) e participou da organização das coletâneas Walter Benjamin: arte e experiência (NAU/EdUFF, 2009) e Filosofia da História (EdUFF, 2014). E-mail: marthadangelo@yahoo.com.br

\begin{tabular}{|l|l|l|l|l|l|}
\hline APRENDER - Cad. de Filosofia e Psic. da Educação & Vitória da Conquista & Ano XII & n. & p. 10-22 & jan./jun.2018 \\
\hline
\end{tabular}


Todos os graus ou nuances de crueza moral, estupidez espiritual e miséria física sempre coexistiram com o refinamento cultivado da vida... e a livre fruição das vantagens da ordem burguesa. (Hermann Lotze, apud Benjamin, 2006, p. 522)

\section{A natureza do saber filosófico}

No prefácio epistemológico do livro sobre o drama barroco alemão, Walter Benjamin faz uma distinção entre conhecimento e verdade que revela a especificidade da filosofia enquanto saber e a diferença desse saber em relação a outros saberes. Junto com essa distinção há uma crítica à forma como a filosofia passou a ser praticada na época moderna, e à tendência de se adotar os procedimentos metodológicos da ciência como modelo. Não se trata, porém, de uma crítica com a pretensão de introduzir um novo método de filosofar, pois o caminho para se chegar à verdade - objeto da filosofia - não pode ser definido a priori pelo sujeito. É preciso levar em conta a natureza da verdade. Neste texto Benjamin apresenta uma alternativa às teorias do conhecimento modernas, que tomam as ciências como modelo, enfatizando a forma de filosofar e a preservação da própria natureza do saber filosófico: "Se a filosofia quiser conservar a lei da sua forma, não como propedêutica mediadora do conhecimento, mas como representação [Darstellung] da verdade, então aquilo que mais importa deve ser a prática dessa forma, e não sua antecipação num sistema.” (BENJAMIN, 2004, p. 14).

A não intencionalidade no caminho e a forma como se busca a verdade pode ser comparada ao processo de construção de um mosaico em seu esforço constante e paciente de organização do todo através da montagem de pequenos fragmentos. A beleza do todo será tanto maior quanto mais se manifestar a singularidade de cada fragmento. Referindo-se à forma do mosaico, Benjamin (2004, p.15) diz que "o conteúdo de verdade (wahrheitsgehalt) se deixa apreender apenas através da mais exata descida ao nível dos pormenores de um conteúdo material (sachgehalt)."

Preocupado em não perder a riqueza dos fenômenos e em preservar a concretude da verdade, Benjamin se inspirou nas colagens surrealistas na construção de seus mosaicos; especialmente nas Passagens, os fragmentos se iluminam reciprocamente, numa montagem que se contrapõe radicalmente à ideia de sistema. Colagem e mosaico apresentam uma 
totalidade móvel sempre aberta à incorporação de novos elementos. Essa forma permite a absorção do imprevisível e do acaso na estrutura fragmentária do texto. Corresponde a essa forma um tipo de escrita que obriga o leitor a se deter em cada frase, e não uma escrita que o arrasta a uma "certeza" através de deduções fortemente articuladas. O estilo de escrita adequado à filosofia deve se pautar pela sobriedade prosaica, mantendo-se distante do encadeamento argumentativo e do tom afirmativo próprio à forma da ciência.

Observando a obra de Kurt Schwitters, artista próximo ao dadaísmo que produziu colagens com palavras e imagens reciclando o que era considerado em sua época "lixo cultural", percebemos uma grande afinidade com o processo de criação de Benjamin. Poemas de sua Merz, art como "An Anne Blume"(Para Ana Flor, 1920) e "The Sacred Sadder's Leather Wrapper" (A pasta sagrada do artesão de artigos de couro, 1922) criam relações entre imagens e palavras associando elementos heterogêneos que no conjunto ganham um novo sentido. A grandiosa instalação Merzbau (Casa Merz, 1923, que ocupava todo o espaço da casa do artista em Hannover), destruída num ataque aéreo em 1943, ou pela Gestapo após a fuga de Schwitters da Alemanha, mostra uma estrutura formal bastante semelhante à que foi utilizada no trabalho das Passagens. A convergência entre o artista e o filósofo nos permite dizer que, fazendo uma espécie de fusão, ou identificação, entre arte e filosofia, eles chegaram aos limites possíveis de uma verdadeira experiência. No ensaio "O Surrealismo" (1929), Benjamin admite que uma politização da arte e da cultura que pretenda derrubar a hegemonia intelectual da burguesia, deve acontecer como experiência viva e fecunda, pautada num conceito radical de liberdade. Mas a ação individual não pode dar conta dessa tarefa. Somente quando as energias da embriaguez, geradas por um materialismo antropológico, fizer com que as "tensões revolucionárias se transformem em inervações do corpo coletivo, e todas as inervações do corpo coletivo se transformem em tensões revolucionárias; terá então a realidade conseguido superar-se, segundo a exigência do Manifesto Comunista" (BENJAMIN, 1994, p.35).

A identificação entre verdade e beleza apresentada no diálogo $O$ Banquete, e a declaração contida neste diálogo de Platão de que "a verdade é bela", ou que a verdade é o conteúdo do belo, adquiriu um sentido novo no pensamento de Benjamin em virtude da maneira como nele se articula essência e aparência. Essa articulação foi ganhando densidade metodológica e um caráter mais materialista no decorrer da trajetória do filósofo. Comentando a distinção entre método de pesquisa e método de exposição em Benjamin, 
Jeanne Marie Gagnebin observou que para ele "não se trata somente de analisar as várias formas de exposição que pode adotar o conhecimento filosófico; mais radicalmente, trata-se de resguardar uma outra dimensão do pensamento e da escrita filosóficos: não levar a conhecimento(s), mas expor/apresentar a verdade" (GAGNEBIN, 2005, p.185).

No prefácio do livro sobre o drama barroco, Benjamin confere aos conceitos um papel mediador entre os fenômenos e as ideias porque desse modo as diferenças e particularidades existentes na empiria poderiam dar concretude à verdade. O papel do conceito neste caso é destacar os elementos extremos dos fenômenos para que estes sejam preservados e se tornem visíveis nas ideias. O fenômeno "será tanto mais profundamente apreendido quanto mais claramente for visto como algo extremo" (BENJAMIN, 2004, p. 21). Se a filosofia se limitar à construção de conceitos, o não idêntico próprio aos fenômenos não terá lugar no pensamento. O conceito, exatamente por mediar fenômeno e ideia, não constitui uma invenção do sujeito imposta ao objeto; ele é inseparável do objeto ao qual se refere, e não algo externo à coisa que é pensada. A estrutura da verdade é da ordem da ideia, e essa é da ordem da linguagem. "Cada idéia contém a imagem do mundo" (BENJAMIN, 2004, p.35), mas, por estar referenciada ao mundo empírico e à história, a imagem precisa ser renovada na ordem das ideias. Tratando da questão da historicidade própria às ideias filosóficas, numa carta a Florens Christian Rang em 9 de dezembro de 1923, Benjamin admitiu que não se alcança a historicidade específica das ideias filosóficas pela história da filosofia, assim como não se chega às obras de arte através da história da arte, mas pela interpretação. As ideias filosóficas "não brilham na luz diurna da história, agem apenas de forma invisível nela" (BENJAMIN, 2004, p. 296),

O papel do conceito e o destaque aos elementos extremos dos fenômenos na formação das ideias é equivalente ao princípio que orienta a produção da imagem na poética surrealista. $\mathrm{Na}$ formação de ambas, se destacam os elementos extremos. No Manifesto de 1924, reproduzindo e incorporando as "palavras sibilinas" de Pierre Reverdy, André Breton (1985, p. 52) afirma:

A imagem é uma criação pura do espírito.

Ela não pode nascer da comparação, mas da aproximação de duas realidades mais ou menos remotas.

Quanto mais longínquas e justas forem as afinidades de duas realidades próximas, tanto mais forte será a imagem - mais poder emotivo e realidade poética ela possuirá... etc. 


\section{O mundo como linguagem}

A compreensão do mundo como linguagem foi exposta por Benjamin no ensaio “Sobre a linguagem em geral e sobre a linguagem do homem", de 1916, que reconhece ser a tarefa fundamental da teoria da linguagem clarificar o porquê da afirmação: "Toda linguagem comunica-se a si mesma" (Jede sprache teilt sich selbst mit) (BENJAMIN, 2011, p.53). O entendimento da imediaticidade da teoria da comunicação espiritual é o elementochave para a dissolução da aparência de tautologia existente na frase: "a essência lingüística das coisas é sua linguagem" (Das Sprachliche wesen der Dinge ist ibre Sprache). No âmbito externo à filosofia, a noção de pureza de linguagem mais próxima desta talvez se encontre naquilo que os surrealistas chamam de "o maravilhoso". Essa pureza foi indicada por Benjamin no ensaio "O Surrealismo", quando ele se refere à linguagem autêntica da poesia surrealista associando-a àquele momento mágico em que "o som e a imagem, a imagem e o som, se interpenetravam, com exatidão automática, de forma tão feliz, que não sobrava a mínima fresta para inserir a pequena moeda a que chamamos "sentido". A imagem e a linguagem passam na frente"(BENJAMIN, 1994, p.22).

Nesse texto há referências ao desaparecimento do Autor e ao abalo do "eu" provocado pela experiência mística e pela experiência com drogas. A expressão usada por Benjamin para designar esse tipo de experiência, de natureza materialista e antropológica, é iluminação profana. Ampliando a experiência humana e elevando-a a um sentido mais profundo, essa iluminação pode servir de propedêutica a uma atuação política. A união das palavras iluminação e profana encarna o princípio de Breton e Pierre Reverdy - de que, quanto mais distantes forem as realidades associadas numa imagem, mais força ela tem - pela aparente incompatibilidade ou contradição entre as palavras "iluminação", que tem uma conotação mística, transcendental, e "profana", que sugere o plano terreno e material. Imbuído desse espírito libertário, Breton escreveu a última frase de Nadja, na qual ele define de maneira muito própria a natureza política da estética surrealista e seu compromisso com a verdade: "A beleza será convulsiva ou não será nada."

Pensando com imagens e refletindo sobre os processos de criação de imagens, na literatura, na fotografia e no cinema, Benjamin contribuiu para um alargamento do sentido do ato de filosofar e sua relação com a linguagem. A força imagética dos objetos fora de moda e a denúncia neles inscrita da ilusão do progresso, foi considerada por ele como a 
mais surpreendente descoberta dos surrealistas. Também valorizou o fato de os surrealistas admitirem a existência de uma potência simbólica e uma dimensão utópica poderosíssima nos contos de fada. "Há contos a escrever para adultos, contos de fada, quase", diz Breton (1985, p. 47) no primeiro Manifesto. Como os poetas do primeiro romantismo alemão, eles se sentiam atraídos pelo mundo dos contos de fadas por encontrarem nele uma comunhão universal e uma comunicação mágica entre as coisas. Benjamin se inclui entre os intelectuais alemães, como Luckács, Siegfried Kracauer e Ernst Bloch, que acreditavam no potencial libertador dos contos de fadas. A função desse gênero literário marginal, desenvolvido oralmente, no final da Idade Média, por artesãos e pequenos burgueses emergentes, seria manter, ainda que de forma recalcada, a esperança de reconciliação do homem com a natureza. Enquanto forma e estrutura narrativa, o conto de fadas se assemelha à linguagem do sonho, evocando um passado remoto que se projeta como desejo futuro, e à linguagem dos místicos.

No ensaio sobre a linguagem, de 1916 Benjamin não aborda especificamente o problema da origem da linguagem humana. A indicação dessa origem na mímese aparece alguns anos depois nos escritos "Teoria das semelhanças" (Lehre vom Ähnlichen) e "Sobre a faculdade mimética" (Über das mimetische Vermögen), de 1933. Neles as especulações sobre os processos geradores de semelhanças e o conceito de semelhança não-física remetem à observação de fenômenos naturais fundados no mimetismo. Além de ressaltar que a capacidade de produzir semelhanças se manifesta de maneira mais acentuada no homem, Benjamin também considera que todas as funções humanas superiores são determinadas pela faculdade mimética. A Teoria indica a brincadeira da criança como "escola" de formação dessa faculdade em diferentes épocas.

A criança, através do jogo da imitação, tenta penetrar no âmago das coisas, estabelecendo com esse exercício ativo e receptivo correspondências mágicas e redes de comunicação com o mundo. A reprodução de sons através da imitação, que teria possibilitado a formação das línguas, se manifesta no balbuciar da criança. Através da combinação de algumas sílabas ela constrói uma linguagem própria (Kindersprache). As práticas de leitura do mundo iniciadas na pré-história da humanidade teriam levado ao surgimento da linguagem oral e ao desenvolvimento de narrativas mágicas que atingiram seu nível mais alto de elaboração nos contos de fada.

À medida que se aproxima da vida adulta, a criança vai perdendo a faculdade mimética; na história da humanidade, a partir da época moderna encontramos apenas “ínfimos resíduos daquelas correspondências mágicas que eram familiares aos povos 
antigos" (BENJAMIN, 1992, p.66). A capacidade mimética dos antigos, estendida para as semelhanças não-físicas, percorrendo tanto o micro como o macrocosmo, alcançou configurações que nós hoje temos dificuldade até mesmo de imaginar. A diferença entre a leitura que o aluno faz do abecedário e a leitura do astrólogo, do futuro nas estrelas, é que a do primeiro não se desdobra nos seus dois componentes, enquanto na do segundo o processo se apresenta nos seus dois estratos: o astrólogo lê a posição das estrelas no céu; a partir daí lê o futuro ou o destino. Benjamin admite que a semelhança não-física está presente em toda leitura. Em tempos muito remotos, a leitura das estrelas, que resultou na astrologia, era capaz de encontrar semelhanças entre os fenômenos celestes e a vida de um homem. Esta maneira de se relacionar com as coisas cria condições para a leitura do que nunca foi escrito, o acesso direto ao livro do mundo. Mas a leitura da palavra e a leitura do livro do mundo operam em registros distintos:

Ler o que nunca foi escrito.' Esta é a leitura mais antiga: a leitura antes de todas as linguagens, a partir das vísceras, das estrelas ou das danças. Mais tarde começaram a utilizar-se os elos de mediação para uma nova leitura, as runas e os hieróglifos. Supõe-se que estes foram estádios pelos quais aquele dom mimético, que fora anteriormente a base da práxis oculta, encontrou o acesso para a escrita e para a linguagem. Deste modo a linguagem seria o grau superior da faculdade mimética e o mais perfeito arquivo das semelhanças não físicas: um médium no qual as forças primitivas de produção e interpretação mimética penetraram de tal modo que conseguiram liquidar as da magia. (BENJAMIN, 1992, p. 68).

\section{O caráter dialético da cultura e o mal-estar na educação}

As novas tecnologias e as possibilidades de reprodução de sons e imagens por meio da fotografia, do rádio e do cinema vêm provocando mudanças profundas na percepção e na comunicação humana. As reflexões de Benjamin nos ensaios "A obra de arte na era de sua reprodutibilidade técnica" e "Pequena história da fotografia" contribuíram significativamente para o aprofundamento do debate em torno deste tema. Algumas questões contidas nesses dois textos retomam elementos do "Prefácio Epistemológico" do livro sobre o drama barroco alemão, conectam-se com o arquivo "N" da obra das Passagens e com as teses "Sobre o conceito de história".

Um ponto fundamental neste conjunto de escritos é a afirmação de um processo de conhecimento capaz de alcançar uma concretude que não reduz o particular a um universal atemporal. $\mathrm{O}$ caráter micrológico e fragmentário do método benjaminiano não 
incorpora plenamente, como observou Adorno (1995b, p. 21), a "ideia de mediação universal que são o fundamento da totalidade em Hegel e Marx." Trata-se, neste caso, de apresentar, como nas colagens dadaístas e surrealistas que mencionamos anteriormente, as significações por meio dos contrastes exibidos na montagem do material.

A preocupação em valorizar a densidade da experiência na busca da verdade levou Benjamin a uma aproximação com os métodos e processos de criação desses artistas. Os princípios metodológicos apresentados nos fragmentos sob a rubrica "Teoria do conhecimento, teoria do Progresso", no arquivo "N" da obra das Passagens, que retomam a ideia do método como caminho indireto enunciada no Prefácio do livro sobre o drama barroco alemão, se assemelham a um tipo de errância como a que foi descrita por Breton em Nadja. Benjamin (2006, p. 499) sugere essa aproximação ao admitir: “o que são desvios para os outros, são para mim os dados que determinam a minha rota" (BENJAMIN, 2006, p. 499). Nessa abertura para o inesperado e para o imprevisível fica implícito o reconhecimento de uma dimensão inconsciente em todo o conhecimento humano e do acaso no curso da história. A opção visceralmente materialista das formulações epistemológicas das Passagens visa "Aplicar à história o princípio da montagem. Isto é: erguer grandes construções a partir de elementos minúsculos, recortados com clareza e precisão. E, mesmo, descobrir na análise do pequeno momento individual o cristal do acontecimento total" (BENJAMIN, 2006, p. 503).

O materialismo e o anti-subjetivismo inerente a esse modo de pensar, que, através da aproximação com o empírico e a utilização da montagem, coloca em questão o conceito burguês de autoria, vai de encontro ao desejo de alguns professores de implantar práticas colaborativas na educação, tanto em processos de aprendizagem como de avaliação. Nessa perspectiva, o apagamento das fronteiras disciplinares permite estruturas curriculares mais livres e novas formas de articulação entre arte, ciência e filosofia. Ações pedagógicas desse tipo encontram resistência na educação escolar porque atingem os pilares da cultura burguesa.

O empirismo materialista das Passagens transpõe fronteiras disciplinares trabalhando com fontes e elementos heterogêneos, como, por exemplo, arquitetura, vestuário, moda e psicanálise. No arquivo "B”, cujo tema é a moda, Benjamin (2006, p. 103) diz que no século XIX “toda a energia onírica de uma sociedade se refugiou com dupla veemência no reino nebuloso, silencioso e impenetrável da moda, no qual o entendimento não a pode acompanhar." Na parte inconsciente e no fetichismo da moda, masculina e feminina, ele encontrou diferentes tipos de perversão, resistências secretas ao amor, jogos de sedução e 
sinais discretos que prenunciavam o futuro. Uma visão antecipada do século XX seria possível pela leitura da moda do século XIX, nas fantasmagorias desta moda:

Dificilmente encontra-se uma peça de vestuário que pode expressar tantas tendências eróticas divergentes e fornecer tantas possibilidades para dissimulá-las quanto o chapéu feminino. Enquanto o significado da cobertura de cabeça masculina seguia estritamente, em sua esfera - a política -, alguns modelos rígidos, as nuances do significado erótico do chapéu feminino são incalculáveis (BENJAMIN, 2006, p. 118).

O caráter dialético da cultura se expressa na contradição inerente ao processo de produção dos bens culturais na sociedade burguesa, exposto por Benjamin na Tese VII Sobre o conceito de história: "Nunca há um documento da cultura que não seja, ao mesmo tempo, um documento da barbárie.” O enfrentamento com o elemento de barbárie presente em todos os documentos da cultura constitui o maior desafio da educação hoje, pois, assim como a produção dos bens culturais não está isenta de barbárie, “também não o está o processo de sua transmissão" (BENJAMIN, 2005, p.70).

Esta contaminação mantém o estado de exceção no qual vivemos. $O$ encadeamento sistêmico que sustenta a barbárie exige um embate constante com os mecanismos de reprodução das instituições, que operam a transfiguração dos fenômenos histórico-sociais em fenômenos naturais.

Abordando essa temática numa entrevista na rádio de Hessen, em abril de 1968, Adorno (1995a, p.155) sustentou a tese de que "desbarbarizar tornou-se a questão mais urgente da educação.” O problema neste caso seria avaliar qual é a potência da educação neste combate. Adorno definiu a barbárie como uma discrepância entre o grau de desenvolvimento tecnológico e os termos correspondentes ao conceito de civilização, que leva as pessoas a uma agressividade primitiva, a um ódio primitivo, um impulso de destruição capaz de colocar em risco a vida em sociedade. No contexto brasileiro atual, especialmente nos últimos dois anos, encontramos inúmeros exemplos ilustrativos dessa definição. As políticas neoliberais, promovendo o aumento da concentração de renda, o desemprego e a insegurança em relação ao futuro, despertaram numa parte da população um ódio visceral aos pobres. A intolerância que contaminou a sociedade vem gerando manifestações ostensivas de racismo, machismo, homofobia e xenofobia. No campo da educação, cultura e segurança pública, fatos e estudos empíricos revelam o crescimento da barbárie, a fragilidade das instituições e a debilidade de nossa democracia.

Dados sobre a criminalidade divulgados em 5 de junho de 2018 no "Atlas da 
Violência 2018" mostram que na década de 2006 a 2016553 mil pessoas foram assassinadas no Brasil, sendo que 324.967 delas tinham entre 15 e 29 anos. Cerca de $70 \%$ desses jovens eram negros, não tinham o ensino fundamental completo e moravam nas periferias das grandes cidades. Estamos entre os 14 países mais violentos do mundo, em 2016 chegamos a um total de 62.517 homicídios. Neste cenário chama atenção a falta de empenho do Estado em apurar os crimes e punir os culpados, a omissão da sociedade em cobrar o cumprimento da lei, a insensibilidade em relação ao genocídio da população negra e pobre, a irresponsabilidade do poder judiciário e o sensacionalismo da grande mídia na cobertura dos fatos.

No campo da educação, analisando a evolução das matrículas estaduais, municipais e privadas na educação básica no Brasil, de 2006 a 2015, o professor Nicholas Davies (2016) mostrou que as redes públicas municipais e estaduais diminuíram, mas as redes privadas cresceram. A região Nordeste foi a que teve maior queda de matrículas estaduais e municipais, agravando assim as deficiências estruturais da educação básica. A rede estadual do Rio de Janeiro foi a que mais diminuiu (-48\%), uma queda altíssima, sobretudo se consideramos que o Rio de Janeiro tem a terceira maior arrecadação de impostos do Brasil. Esse fracasso contribuiu para o sucesso da rede privada, que se tornou a maior do Brasil em termos percentuais, sendo o único estado em que a rede privada da educação básica é maior que a estadual. A pesquisa mostra o descompromisso dos governos, especialmente o do estado do Rio de Janeiro, com a educação pública e seu conluio com a educação privada.

Além dessas perdas, e outras, como o desvio de recursos da merenda escolar no governo do estado de São Paulo durante vinte anos, a educação vem sendo atingida também por movimentos e projetos, como o do "Programa Escola sem partido", que, a pretexto de impedir a doutrinação ideológica nas escolas, fere a liberdade de expressão, viola a Constituição e ignora a Lei de Diretrizes e Bases da Educação (LDB), que garante a autonomia administrativa e pedagógica dos sistemas de ensino. Trata-se neste caso de um "Programa" que pretende desfazer o percurso democrático realizado no campo da educação após 20 anos de ditadura militar, reinstalando a censura e a repressão contra educadores nas escolas. Utilizando um discurso moralista, e se apresentando como guardiões da família e dos bons costumes, os ideólogos e apoiadores deste "Programa" repetem a velha retórica do risco crescente de violação da consciência dos jovens por “doutrinadores comunistas" travestidos de educadores, para justificar suas propostas. O obscurantismo desse grupo chegou ao ponto de estimular uma campanha contra Paulo Freire, o educador brasileiro mais reconhecido e de maior prestígio internacional. Tamanho 
conservadorismo mostra a atualidade e a necessidade de uma releitura de obras como Pedagogia do Oprimido, para um combate mais efetivo a todas as formas de manipulação e colonização.

Em novembro de 2017, as agressões à filósofa Judith Butler no aeroporto internacional de Guarulhos e na porta do Sesc Pompéia, em São Paulo, por manifestantes exaltados, que de forma grotesca queimaram um boneco que retratava a filósofa como uma bruxa, foram motivados por seu suposto apoio ao que ficou rotulado por ultraconservadores como "ideologia de gênero". A ignorância e os preconceitos que animam manifestações desse tipo atuam, em sintonia com os interesses econômicos neoliberais, disseminando o medo para impedir iniciativas de resistência e revolta contra a opressão econômica e o colonialismo cultural

No âmbito das artes, protestos e atos violentos também alcançaram uma dimensão inusitada em 2017. Entre os inúmeros casos de intolerância e restrição à liberdade de expressão, destacam-se o fechamento da mostra pelo Santander Cultural QueermuseuCartografias da Diferença na arte brasileira, em Porto Alegre, e as acusações de pedofilia e perseguição ao artista Wagner Schwartz pela realização da performance de 40 minutos La Bête, na abertura do $35^{\circ}$ Panorama da Arte Brasileira, no Museu de Arte Moderna (MAM) de São Paulo. Vale notar que essa performance já havia sido realizada muitas vezes, desde 2005. Nos dois casos, as censuras foram motivadas pelas mensagens de ódio e notícias falsas veiculadas na internet por políticos conservadores, grupos religiosos e organizações de extrema direita como o Movimento Brasil Livre (MBL). Os curadores das exposições, Gaudêncio Fidélis e Luiz Camillo Osorio, foram intimados a depor na CPI dos Maus-tratos Infantis no Senado Federal, e a propagação do vídeo de Schwartz, que reduziu a performance ao momento em que uma criança, acompanhada da mãe, toca os pés do artista, gerou um enfrentamento com uma instituição do porte do MAM de São Paulo, e ataques contra um artista, que foi obrigado a depor numa delegacia, recebeu ameaças de morte e foi alvo de notícias mentirosas nas redes sociais sobre um suposto suicídio e linchamento a pauladas.

Todos esses fatos mostram que estamos vivendo um momento de perigo nesse mundo bombardeado por fake news. Cada vez mais se exige dos educadores o compromisso com a verdade e o combate à barbárie. Nesse enfrentamento, é necessário que os discursos se desdobrem em ações. Surpreendentemente, algumas das mais importantes que tivemos 
nos últimos três anos foram realizadas por adolescentes. Em 2015 os estudantes secundaristas de São Paulo ocuparam centenas de escolas em protesto contra a reorganização escolar imposta pelo governo Alckmin, que, depois de quase 60 dias, acabou recuando e suspendendo a medida. Em 2016, inspirados nessa experiência, milhares de estudantes secundaristas e universitários começaram uma luta contra as "reformas" do governo Temer e dos governos estaduais. Enfrentando a repressão das autoridades, a criminalização da grande mídia, e os ataques de organizações de direita, os estudantes deram uma aula de luta e resistência contra a precarização, privatização, sucateamento e corrupção na educação pública. Com um vigor extraordinário, jovens de todo o país se levantaram contra a PEC 241/55, ou "PEC do fim do mundo", e fizeram o maior movimento de ocupações de nossa história.

Nesse processo, novas linguagens e formas de organização do espaço escolar foram surgindo numa explosão de democracia: assembléias horizontais, aulas públicas, mutirões de limpeza, atividades culturais, cozinha coletiva, estratégias de segurança e comunicação, mobilização da comunidade para doações de alimentos e solidariedade, diálogos transversais com professores, pais, movimentos sociais, artistas e ativistas. Ocupando e reinventando a escola os estudantes aprenderam e ensinaram o que é autonomia no sentido forte. Questões aparentemente muito abstratas, técnicas e distantes dos alunos, como projeto pedagógico, currículo, disciplina e gestão escolar foram trabalhadas no dia a dia das ocupações com muita liberdade, coragem e verdade. O sopro de vida da primavera secundarista, fascinante como os jogos e colagens surrealistas, dissipou por um momento o sentimento de impotência e a angústia dos que não vêem o curso da história como progresso, mas como catástrofe. Os que aprenderam com Benjamin (2006, p. 516) que "O progresso não se situa na continuidade do curso do tempo e sim em suas interferências, onde algo verdadeiramente novo se faz sentir pela primeira vez, com a sobriedade do amanhecer."

\section{REFERÊNCIAS}


ADORNO, Theodor. Educação e emancipação. Rio de Janeiro: Paz e Terra, 1995a.

Sobre Walter Benjamin. Recensiones, artículos, cartas. Tradução: Carlos Fortea.

Madri: Ediciones Cátedra, 1995b.

BENJAMIN, Walter. Sobre arte, técnica, linguagem e politica. Tradução: Maria Luz Moita, Maria Amélia Cruz e Manuel Alberto. Lisboa: Relógio D’água, 1992.

. “O Surrealismo". In: BENJAMIN, Walter. Magia e técnica, arte e política: ensaios sobre literatura e história da cultura/Walter Benjamin. Tradução: Sérgio Paulo Rouanet. $7^{\mathrm{a}}$ Edição. São Paulo: Brasiliense, 1994. (obras escolhidas v. 1).

. Origem do Drama Trágico Alemão. Tradução e notas: João Barrento. Lisboa: Assírio e Alvim, 2004.

"Teses sobre a filosofia da história" in: LÖWY, Michel. Walter Benjamin: aviso de incêndio. Uma leitura das teses "Sobre o conceito de história". Tradução de Wanda Nogueira Caldeira Brant. Tradução das teses: Jeanne Marie Gagnebin e Marcos Lutz Müller. São Paulo: Boitempo Editorial, 2005

- Passagens. Organização da edição Willi Bolle, Tradução do alemão de Irene

Aron; Tradução do francês de Cleonice Paes Barreto Mourão. Belo Horizonte: Editora UFMG; São Paulo: Imprensa Oficial do Estado de São Paulo, 2006.

Escritos sobre mito e linguagem. 1915-1921. Organização, apresentação e notas:

Jeanne Marie Gagnebin. Tradução: Susana Kampff Lages e Ernani Chaves. São Paulo: Livraria Duas cidades; Editora 34, 2011.

"A obra de arte na era de sua reprodutibilidade técnica". In: CAPISTRANO, T.

(org.). Benjamin e a obra de arte: técnica, imagem e percepção. Tradução: Marijane Lisboa e Vera Ribeiro. Rio de Janeiro: Contraponto, 2012.

BRETON, André. Nadja, São Paulo: Cosac Naify, 2007. . Manifestos do Surrealismo. Tradução: Luis Forbes. São Paulo: Brasiliense, 1985.

DAVIES, Nicholas. Números da educação: o que revelam e escondem? Revista Aleph, Niterói, Ano XIII, número 27, p. 67-94, dez. 2016.

GAGNEBIN, Jeanne Marie Do conceito de Darstellung em Walter Benjamin ou verdade e beleza. Kriterion, Belo Horizonte, v. 46, n. 112, dez. 2005.

IPEA; Fórum Brasileiro de Segurança Pública (FBSP). Atlas Brasileiro de Segurança Pública 2018. 
Recebido em: 20 de abril de 2018. Aprovado em: 19de junbo de 2018. 